\title{
A Grande Aventura da Química
}

\author{
Lição plenária proferida no XVIII Encontro Nacional da SPQ Universidade de \\ Aveiro, 25-27 Março 2002
}

PIERRE L A S Z L O

Ciência é sinónimo de aventura, pelo menos em dois aspectos significados: no que diz respeito ao espírito de aventura que instiga muitas descobertas das maravilhas da Natureza; e também à aventura intelectual de dar um sentido convincente, coerente às observações. Uma vez que a química é uma das ciências, partilha de tal ousada curiosidade.

Mas não será a química especial? Não haverá razões para que a ciência da transformação da matéria possa implicar ainda mais audácia do que, digamos, a astronomia ou a antropologia?
A palestra levantará esta questão e outras relacionadas, tais como: proliferação de novos produtos químicos e riscos associados; capital de risco e indústria química; grandes aventureiros da química do passado, tais como Russell Marker, o fundador da Syntex; que viagens de descoberta poderemos nós actualmente aconselhar um jovem a realizar?

A palestra evitará tecnicismos e evidenciará a dimensão cultural, essencial da química.

\section{Introdução}

Por acordo com o Professor Joāo Rocha, escolhi a aventura de química como tema da minha exposição de hoje, introdutória ao conjunto desta reunião da Sociedade Portuguesa de Química. Começarei por vos fazer lembrar o que significa a palavra "aventura".

0 espírito de aventura poderia ser definido como um traço de carácter que nos empurra para fora do nosso ambiente usual, das nossas coordenadas culturais e educativas, e que nos incita a descobrir algures o que é diverso. 0 espírito de aventura, no investigador científico é sobretudo saber não virar as costas e, pelo contrário, acolher o imprevisto, o estranho, o bizarro e o extravagante (o Unheimlich, para utilizar o termo freudiano). Muitas descobertas foram, portanto, o resultado do espírito de aventura dum investigador confrontado com um achado imprevisto, como seja o teflon por Plunkett da firma Dupont de Nemours ou o aspartame por James M. Schlatter da G.D. Searle.
A aventura intelectual é a transposta, no mundo do espírito, no da razão pura, deste espirito de aventura. Reenquadrar conceitos define esta aventura intelectual, que se identifica com uma mudança de paradigma, no sentido que Thomas Kuhn the deu. A aventura intelectual é sinónimo de abertura. 0 espírito abre-se subitamente a toda uma gama de possibilidades, inéditas e inebriantes. A descoberta dos fulerenos é um belo exemplo de aventura intelectual. As regras de simetria de Woodward-Hoffmann são outro belo exemplo. Pode dizer-se que se abriram novos capítulos da química, a partir de qualquer destas aventuras intelectuais.

\section{A particularidade da química}

Terá a química, mais do que outras ciências tais como a biologia, a astronomia ou a antropologia, uma dimensão aventurosa, uma vocação para a aventura? A resposta, se não é evidente, não é menos afirmativa. Vejo duas razōes principais para que o ofício de químico seja intrinsecamente aventuroso. Um dos factores é prático, o outro é epistemológico.

O primeiro provém da nossa herança de feiticeiros, de ferreiros e de alquimistas. Nós temos gosto pelo risco, porque aprendemos a dominar os perigos inerentes ao trabalho de laboratório. 0 químico é, entre os cientistas, a pessoa que trabalha com uma bata, com óculos de segurança, numa "hotte", com um extintor ao seu lado. Qualquer laboratório de química tem um duche, para acudir ao desafortunado em vias de pegar fogo. Conheço um químico que viu o seu próprio irmão falecer num acidente de laboratório, onde se incendiou.

Nós, químicos, somos mestres do fogo. Irmãos e irmãs dos alpinistas, dos trepadores, somos também familiares do imprevisto e do acidental. É preciso coragem para manipular certos reagentes, certos substratos que nós sabemos perigosos. Para citar casos concretos, o sulfureto de carbono é um solvente perigoso, pela sua toxicidade à respiração e pelo seu ponto de deflagração, à temperatura ambiente. Um outro exemplo 
seria o diazometano. Mas não insisto mais neste ponto: na longa lista dos produtos químicos perigosos e, por isso, de manipulação delicada, nós conhecemos bem todos os que nos dizem respeito.

O segundo factor, de tipo epistémico, é a atitude forçosamente lúdica do químico ou da química no seu corpo-a-corpo com a matéria. O químico é a pessoa que mistura coisas "para ver o que dá". 0 químico organiza, com efeito, encontros, interacções, ou colisōes entre os corpos, a fim de obter o espectáculo dum resultado, que nunca é totalmente previsivel. Assim, o químico procura constantemente obter o espectáculo dum imprevisto. Dito doutro modo, a ciência química abre-se permanentemente a novos territórios, graças a esse carácter intrinsecamente aventuroso dos químicos.

A química podia entâo definir-se como sendo a sua própria transcendência. De entre as ciências, a química é a que não só não fica dentro das suas fronteiras, mas que vai constantemente para além dessas fronteiras. A boa química, a grande química é a da excursão para fora das fronteiras, a da transgressão das normas. Não é surpreendente que toda uma química se tenha construido sobre a investigação deliberada do anormal; e que a construção de arquitecturas a priori patológicas, pela sua instabilidade ou pela sua bizarria, é uma constante do pensamento químico. Darei, como exemplo, a síntese do cubano por Philip E. Eaton e a, relativamente recente, do octanitrocubano que é, se não me engano, uma das moléculas mais explosivas jamais elaboradas.

\section{Os Descobrimentos e o nascimento da química}

A química constituiu-se, nos séculos dezassete e dezoito, durante o grande periodo dos Descobrimentos, depois do periodo inaugurado pela primeira viagem de Cristóvão Colombo ao Mundo Novo, em 1492, de Vasco da Gama à Índia, em 1498 e de Pedro Álvares Cabral ao Brasil, em 1500. Por um lado, sucederam-se as explorações geográficas por todos os azimutes (John Cook,
Bougainville, La Pérouse, Kotzebue, etc.) e, por outro, a colonização e a exploração comercial.

As naus retornavam à Europa carregadas de ouro e de prata. Mas não traziam só metais preciosos. Traziam também substâncias naturais orgânicas, também elas preciosas; daí a sua análise, daí as aplicações diversas que marcaram os começos da química e a tornaram, subitamente, numa ciência das substâncias da natureza e das suas imitaçōes artificiais.

Os navios espanhóis e portugueses transportavam todas estas mercadorias exóticas. Foram necessários dois ou três séculos para que a civilização europeia integrasse dezenas, centenas de novos produtos de consumo, de espécies novas de animas e de plantas, provenientes do resto do planeta, sobretudo das Índias e das Américas. Lembremos o peru, as batatas, o milho e o tomate para citar apenas alguns dos numerosos alimentos que foram desde logo aclimatados à Europa.

Para além de géneros alimentares, os negociantes também traziam madeiras de cor para tingir estofos, como o pau brasil, que deu o nome ao Brasil, ou a madeira de Campèche. Introduziram perfumes exóticos, como o patchuli, das Índias, perfume por que os britânicos são doidos ainda hoje. Puseram no mercado bálsamos, como o bálsamo de benjoim, que nós devemos, como tantos outros produtos do Oriente, aos navegadores árabes; e daí deriva o composto químico e o nome do nosso moderno benzeno. Porque os quimicos, desde 0 século XVII, e manuais como o de Lémery, descreviam, estudavam e analisavam todas estas novas substâncias.

Durante a mesma época, a farmacopeia da Europa enriquecia-se de poderosos medicamentos de importação, frequentemente de origem indiana e sul-americana. No primeiro caso é de citar a contribuição do médico e naturalista português Garcia de Orta, que foi viver para Gôa no século XVI. Através do seu livro 'Colóquios dos Simples e Drogas Medicinais da Índia', obra pioneira da ciência experimental moderna, deu a conhecer à Europa culta a riqueza e os múltiplos segredos da flora indiana. No segundo caso, citarei somente a quinquina (ou quina), que nós devemos à condessa espanhola de Chinchón, muIher do vice-rei do Perú. E o curare que foi trazido por La Condamine, um académico francês membro da expedição de medida do meridiano terrestre na vizinhança do equador, da descida do curso integral do Amazonas que ele fez no regresso. Foi também La Condamine que trouxe do Brasil amostras de cauchu, o que iniciou, após Pierre-Joseph Macquer ter encontrado solventes que o dissolviam, a era moderna de utilização deste extraordinário material elástico. Outra substância natural, igualmente importada da América, também ela revolucionária para a civilização europeia, foi o café.

Depois deste rápido sobrevoo do impacte das viagens de descoberta na sua metrópole de origem, gostava de aprofundar um pouco a história dum destes produtos vindos de longe, o vermelho de cochinilha, de origem mexicana. 0 insecto Dactylopius coccus vive em cactos do género Opuntia. $\mathrm{O}$ abdómen das fêmeas contém um poderoso corante vermelho, Os cadáveres de dois mil insectos fornecem um grama de vermelho de cochinilha. Desde a conquista do México que este corante foi importado pela Europa, onde tomou o lugar do carmim, proveniente do quermes, uma vez que o vermelho de cochinilha continha uma concentração dez vezes maior do corante. Esta importação prosseguiu pelo menos durante dois séculos. Recordo-me, pessoalmente, da utilização do vermelho de cochinilha pela Madame Nellie Bramwell, em Southwell, nas Midlands, nos finais dos anos quarenta. Ela utilizava-o para decorar os bolos que fazia.

Em 1710, Herr Diesbach, um fabricante berlinense de corantes, manipulava o vermelho de cochinilha. Com o fim, assim parece, de o purificar decidiu precipitá-lo. Para isso, juntou potassa. E ficou estupefacto com o resultado que observou, o vermelho tinha-se metamorfoseado de azul intenso. Diesbach acabara de descobrir o azul da Prússia. 
Diesbach tentou compreender a razão desta descoberta fortuita e interrogou o seu fornecedor de potassa. Apercebeuse de que esta estava contaminada com vitriolo de marte, isto é, sulfato de ferro. Diesbach conservou o seu procedimento secreto até 1724 , ano em que Woodward descobriu uma outra via de acesso ao mesmo azul da Prússia.

Woodward fez deflagrar quatro onças de salitre com quatro onças de tártaro. Depois misturou o produto, que suponho ser carbonato de potássio, com quatro onças de sangue de boi. Após calcinação, adição de duas onças de vitríolo verde e de oito onças de alunite em solução alcalina, isolou o cobiçado precipitado azul. No mesmo ano de 1724 , Brown também conseguiu fabricar o azul da Prússia, substituindo o sangue por carne. No ano seguinte, em 1725, Geoffroy preparou o azul da Prússia a partir, quer de lã, quer de cornos de veado.

Em 1752, Macquer, que mencionei atrás a propósito do cauchu, observou o azulamento do ferro em contacto com uma solução alcalina, devido a uma substância trazida ou retirada pela base. Nos anos 1780, Guyton de Morveau, e independentemente, Carl Scheele, constataram a formação dum ácido, quando tratavam o azul da Prússia com ácidos, que foi desde logo denominado ácido prússico. Em 1815, Gay-Lussac conseguiu identificar o ácido prússico com aquilo a que chamamos desde então ácido cianídrico. Finalmente, em 1936 Keggin e Miles determinaram por meio de raios $X$ a estrutura cristalográfica do azul da Prússia e de complexos similares. Estes compostos têm em comum uma estrutura cúbica, na qual os vértices adjacentes são átomos alternativamente de ferro (II) (dois) e ferro (III) (três), sendo as arestas ocupadas por grupos cianeto, enquanto que iōes potássio e moléculas de água alternam nos centros dos cubos.

Mas que aventura! Que extraordinário romance de aventuras é a história do azul da Prússia. Ela ilustra bem um aspecto do meu argumento, as viagens das descobertas, nas quais tantos portugueses se tornaram ilustres, foram responsáveis pela introdução de milhares de substâncias novas que era necessário estudar e elucidar nos laboratórios da química nascente. $E$, notem bem, dezenas de milhares de compostos químicos tiveram histórias assim animadas, pitorescas e ricas em desenvolvimentos e aplicações imprevistas como o azul da Prússia.

E passo agora a apresentar-Ihes um confrade de Diesbach, um outro aventureiro da química. Escolhi um aventureiro do século vinte, para vos convencer que a aventura química continuou para além do século dezoito.

\section{Um aventureiro da química, Russell Marker}

Conheço pessoalmente, tanto na Bélgica como em França, muitos químicos que são verdadeiros prospectores. Partem à aventura pelo mundo fora, até partes remotas de África, de Madagáscar, das ilhas de Sonda e dai trazem plantas que Ihes parecem prometedoras pelas substâncias naturais que escondem, e que os feiticeiros locais Ihes indicam. Deixem-me lembrar-Ihes agora somente a nossa divida colectiva para com o criador da sintese industrial das hormonas esteróides, Russell Marker.

No início dos anos 1930, os químicos, à semelhança dos insectos, fabricavam moléculas de esteróides hormonais a partir do colesterol ou do estigmasterol. Os rendimentos eram maus e, por isso, o preço de custo era elevado, mil dólares por grama para a progesterona.

Russell Marker era um químico que trabalhava no domínio dos esteróides, primeiro no Instituto Rockefeller, e depois, a partir de 1934, no Pennsylvania State College. Ele procurava fontes vegetais ricas em esteróides. Decidiu explorar as possibilidades da diosgenina. Durante uma estadia que fez no Texas, no fim do ano 1942, Marker apercebeu-se da existência de uma dioscoreácea mexicana com tubérculos gigantes, com peso que podia atingir uma centena de quilogramas, o que the pareceu uma fonte prometedora de diosgenina.
Partiu para o México. Em Janeiro de 1942, a embaixada dos Estados Unidos no México pôs Marker em contacto com um botânico mexicano. Puseram-se a caminho para fazer a colheita destas plantas, conhecidas localmente pelo nome de cabeza de negro, no Estado de Veracruz. Marker alugou um camião. 0 botânico chegou ao encontro na companhia da sua namorada, da sua mãe a servir de chaperon e de um intérprete. Recusou-se a avançar enquanto Marker não aceitou esta equipa heteróclita, na sua totalidade.

Esta primeira expedição revelou-se um fiasco. Cinco dias mais tarde voltaram ao México de mãos vazias. Não tinham encontrado a cabeza de negro. Sem se sentir desencorajado, Marker tornou a partir, sozinho, para o campo mexicano, num autocarro. Regressou a Penn State trazendo na mala uma amostra desse inhame. Em Outubro de 1942, Marker que entretanto tinha conseguido convencer o presidente-director geral da empresa farmacêutica Parke-Davis do interesse deste empreendimento - voltou a partir para o México, com metade das suas economias.

Quando regressou de novo a Penn State, trazia consigo o extracto de cerca de dez toneladas de tubérculos de cabeza de negro (Dioscorea composita e Dioscorea terpinapensis). No laboratório de um colega, converteu este extracto em progesterona. Obteve cerda de três quilogramas. O colega em questão, a quem tinha cedido um terço como retribuição pela utilização do laboratório, vendeu-a a oitenta dólares o grama.

Durante a sua estadia no México, Marker tinha concluido um acordo com o proprietário dos Laboratórios Hormona para fundar uma firma, denominada Syntex, fabricante de esteróides a partir das cabezas de negro, igualmente conhecidas na América Latina por barbasco. Em 1944, com os métodos que tinha afinado, Marker já fabricava anualmente trinta quilogramas de progesterona e dez quilogramas de desidro-isoandrosterona.

O seguimento da história é mais sórdido. Marker viu-se espoliado da sua 
parte $(40 \%)$ de fundador da Sintex. Tentou fundar uma sociedade rival mas foi rapidamente obrigado a fechar a loja. Nos principios de 1949, Marker abandonou a química. Ainda hoje, os métodos de Marker continuam a ser aplicados a 60000 toneladas de dioscoreáceas mexicanas por ano.

\section{Uma aventura química contemporânea}

Os salsicheiros há muito que utilizam os nitritos, como conservantes e para manter a carne vermelha. Ora, nos anos 60 os nitritos foram considerados tóxicos. Com efeito, o estômago transforma-os noutras moléculas, denominadas nitrosamidas, que são cancerigenas.

Durante a década que se seguiu aos anos 70, Steven Tannenbaum, um toxicólogo do MIT, estudou os efeitos de nitritos e de nitratos no organismo. Descobriu que bactérias da nossa saliva transformavam nitratos em nitritos. Mas teve uma grande surpresa quando constatou que a urina dos seus pacientes continha mais nitratos do que aqueles que tinham entrado no seu sistema digestivo. A aventura química reserva pois surpresas, observações muito surpreendentes.

Depois de se ter assegurado de que não cometera qualquer erro, o Doutor Tannenbaum decidiu seguir esta nova pista. A via que o conduziu a uma solução foi iniciada com uma das suas pacientes que, no decurso de uma experimentação sofreu uma infecção intestinal. Ficou estupefacto porque a urina desta senhora continha uma quantidade monumental de nitratos!

Experiências posteriores mostraram ao Doutor Tannenbaum que essa quantidade anormalmente elevada de nitratos, que também se apresentava no sangue, era uma consequência duma resposta do sistema imunitário - que protege o organismo das agressões bacterianas e cujas reacções são por vezes tão fortes que o próprio organismo sofre com isso.

Conversou com um colega bioquímico, - Doutor Michael Marletta, com o qual mantinha o excelente hábito de tomar regularmente o café. E porque a aventura quimica se enraiza na interdisciplinaridade, Marletta identificou as células produtoras dos nitratos excedentários como sendo macrofagos, que sāo células do sangue semelhantes aos glóbulos brancos. Eles têm um papel-chave contra as invasões bacterianas, exterminando-as com armas quimicas, entre as quais se encontra a água oxigenada. Marletta mostrou que os macrofagos transformam um dos aminoácidos provenientes da alimentação, a arginina, num composto chamado citrulina, acompanhado de nitritos e de nitratos. A produção de nitratos, em consequência de uma infecção intestinal, foi assim elucidada, mas alguma coisa dizia ao Doutor Marletta que faltava o elo de ligação.

A peça que faltava neste puzzle veio de um sector a todos os títulos inesperado. O Doutor Robert Furchgott, de Nova lorque, tinha descoberto em 1980 uma substância que denominou EDRF, que actuava sobre os músculos lisos, provocando em particular a dilatação dos vasos sanguineos. Assim que leu o artigo de Furchgott, Salvador Moncada, um investigador dos laboratórios farmacêuticos da empresa Wellcome, em Inglaterra, convenceu-se que o tal factor misterioso, com a sigla indecifrável EDRF, podia muito provavelmente identificarse com o óxido nítrico NO. Ele tinha em mente uma outra publicação, de autores alemães que tinham mostrado que o óxido nítrico é o princípio activo da nitroglicerina, que os cardíacos tomam com o nome de trinitrina. Ferid Murad tinha demonstrado em 1977 a libertação de NO pela nitroglicerina.

Moncada demonstrou então um "desenrascanço" digno dum habilidoso: ele precisava de dosear o óxido nítrico produzido pelas células dos vasos sanguineos. Ora, os motores de explosão, como os dos automóveis e dos camiōes, produzem uma mistura de óxidos de azoto, tóxica. É uma das grandes causas da poluição atmosférica nas cidades. Assim, ele adaptou às suas necessidades um dispositivo de medida do conteúdo dos gases de escape em óxidos de azoto . A 'bricolage' é um dos ingre- dientes activos da aventura química! Moncada demonstrou entâo que as células que se encontram nas paredes dos capilares sanguíneos libertam de facto óxido nítrico. Ele publicou este resultado. Luis Ignarro, da Universidade da Califórnia em Los Angeles, publicou também, em 1986, independentemente de Furchgott, a paridade absoluta do EDRF e do NO.

Entretanto, o Dr. Marletta tinha começado a transportar a mobília para o seu novo laboratório, na Universidade de Michigan, em Ann Arbor, no estado do mesmo nome. Numa das viagens, ele aproveitou uma mudança de avião no aeroporto de Denver e algumas horas de espera para reduzir o atraso de leitura da sua documentação bibliográfica. Que bem Ihe fez! Deste modo descobriu o artigo de Moncada. 0 acaso, como este da escala em Denver, é um outro factor determinante da aventura química.

Foi o acaso que deu a Marleta o elo que faltava. Precipitou-se para o MIT. Ao fim de apenas uma semana, ele e o seu amigo Tannenbaum tinham demonstrado que também os próprios macrofagos eram capazes de produzir o óxido nítrico NO. Isso serve-Ihes, em particular. para envenenar e destruir as células, em proliferação rápida, dum tumor canceroso.

Uma outra porta que se abriu com estudos recentes, que não posso desenvolver aqui, mostra que o óxido nítrico, sempre ele, tem um papel fundamental no cérebro: é um neurotransmissor, isto é, um dos mensageiros químicos, viajantes ao longo dos neurónios e responsáveis pela actividade cerebral e nervosa.

Assim, o óxido nítrico assegura sozinho desempenhos fisiológicos tão diversos e dispares como a inibição da contracção (e portanto a dilatação) dos músculos lisos, uma acção anti-tumoral e a mediação química da actividade cerebral! Ele intervém também no choque séptico, pela sua libertaçāo maciça. É a mesma molécula de NO que explica a acção do Viagra como remédio para a impotência masculina. Este medicamento liberta NO, cuja acção vasodilatadora se traduz, entre outras, por uma 
erecção. E terá também um papel olfactivo...

Esta versatilidade do NO só foi possive ser estabelecida graças a investigadores de países e horizontes diversos. Viva a pluridisciplinaridade, criadora, com a literatura científica em aberto, duma manifestação conceptual tão magnífica, que se pode gozar antecipadamente numerosas aplicações benéficas. É, desde já, claro que o óxido nítrico não é só utilizado pelos organismos animais. Nas plantas, funciona como um sinal para se iniciarem as reacções de defesa contra diversos patógenos, como investigadores americanos acabaram de o demonstrar (Nature, 6 Agosto 1998).

\section{A toda a volta...}

A aventura tem uma dimensão ética. A ela consagrarei toda a segunda parte desta palestra. Considerada dum aspecto normativo, qualquer aventura humana se enquadra, com efeito, entre dois limites, uma permissividade excessiva e outra igualmente extrema frilosité. Comecemos pela primeira, uma vez que ela prejudica a profissão no seu todo. Ela dá-nos uma imagem de marca detestável, a do químico-poluidor. Refiro-me à proliferação dos produtos químicos em constante aceleração. É suficiente para tomarmos consciência, lembrarmo-nos do número de produtos químicos actualmente referenciados nos Chemical Abstracts. Este número aproxima-se de 26 milhōes. Quando em 1960 me iniciei na carreira de químico, esse mesmo número era cerca de 10 milhões. Cresceu, portanto, duzentos e sessenta por cento em 40 anos. Será isto um progresso? Ou será antes uma regressão, uma vez que ignoramos quase todo o impacte biológico das novas moléculas que sintetizamos?

A fábula do aprendiz de feiticeiro é pertinente. Conhecemos também o logotipo dos dicionários Larousse, com a divisa "Je sème a tout vent", qualquer coisa como "Semeio a toda a volta": por uma dessas ironias de que a História não é parcimoniosa, o que no século XIX significava disseminação do saber em todas as camadas da sociedade meta- morfoseou-se, de boa fada em bruxa, em poluição do ambiente, quer dizer, em disseminação da ignorância e em compostos quimicos nocivos injectados no oceano e na atmosfera. Como é que chegámos a isto?

Quais são as justificações avançadas que apoiam uma tal proliferação? A primeira é a inovaçāo. Demasiados colegas confundem de boamente, a produção dum novo composto químico ainda não descrito, inédito portanto, com uma verdadeira inovação, criadora de saber e prenhe de potencialidades benéficas para a humanidade. Culpados desta assimilação lexical, tomam-na como desculpa para sintetizar com toda a força séries de moléculas ("metilo - etilo propilo - butilo - futilo", como dizia o outro) que não interessam a ninguém.

Este comportamento cego é uma perversão (i) do trabalho científico (qual é afinal o problema a resolver?); (ii) do financiamento da investigação (haverá algum beneficio para a colectividade?); (iii) da publicação dos periódicos científicos (porquê abater árvores para imprimir textos que ninguém lerá?).

Respondemos habitualmente a estes argumentos: "isto servirá para qualquer coisa ou para qualquer pessoa, um dia destes". Esta resposta hipócrita corresponde à abdicação de responsabilidade. Eu pretendo com efeito que, à imagem da paternidade duma criança, sejamos cada um de nós integralmente responsáveis por qualquer molécula nova posta no mundo e, portanto, introduzida na quimiosfera em que o planeta se tornou doravante.

Uma outra linha de defesa é estatistica. Sabe-se que é preciso sintetizar 10000 moléculas diferentes para se obter um medicamento útil. Esta justificação é a do utilitarismo, acoplada ao empirismo duma "investigação" edisoniana, por tentativa e erro. É o caso da química combinatória - note-se de passagem o pleonasmo - quer dizer, o obscurantismo, que é um insulto a qualquer trabatho intelectual, guiado em principio pela razão e não pelo acaso. Fazer não importa o quê, não importa como, isto não é verdadeiramente a aventura química!
No outro extremo, dizia eu, encontra-se uma frilosité excessiva. Esta esterilização do gosto e do sentido de aventura é a acção, sobretudo, dos organismos de gestão da investigação científica. Esta última, por necessidade intrinseca, é imprevisível, caótica, vai em todos os sentidos. É rebelde a uma boa organização, como a entendem os burocratas. Estes preferem essencialmente uma investigação, por um lado, repetitiva e, por outro, enclausurada em alvéolos de especialização. Encorajam a pluridisciplinaridade, mas de maneira formal. Eles entendem-na como colaboração - vós conheceis isto tão bem como eu - entre um industrial de Parma, um físico-químico de Reading, um analista de Lisboa e um modelizador de Toulouse. Trata-se duma polvilhação de créditos obedecendo a critérios políticos; e isto não tem nada a ver com a realidade da investigação científica.

\section{Bandidos e piratas da química}

Vou agora evocar rapidamente o negativo da imagem da química, vivida como uma bela aventura, que Ihes apresentei até aqui. Como qualquer profissão, a nossa tem uma fracção da sua população constituída por pessoas pouco escrupulosas, algumas mesmo criminosas. Estou a pensar nos químicos que trabalham nas oficinas da multinacional da droga a fabricar opiáceos, anfetaminas ou esteróides anabolisantes. Lembremos o Professor Lester Friedman, da Universidade Case-Western Reserve, em Cleveland. Era um dos grandes nomes da síntese orgânica. Foi preso no aeroporto JFK de Nova lorque, disfarçado com uma falsa barba e transportando na sua mala o fornecimento anual de LSD para o território americano, que ele e os seus associados fabricavam clandestinamente para a Máfia, no parque industrial da Universidade Louvain-laNeuve (Laboratórios Le Clocheton).

Há nisto uma actividade inegavelmente criminosa. Mas quase todos nós cometemos actos repreensiveis na nossa prática quotidiana. 0 perigo mais insidioso provém da investigação de imitação, a me-too chemistry, como a denominaram. Muitos colegas, em vez de fazerem 
um esforço de imaginação, contentamse em seguir o movimento, como carneiros de Panurge, e transpõem as realizações para a moda. É muito mais fácil. E muito tentador, pois a ciência quimica presta-se particularmente bem a estas práticas. Por exemplo, tira-se partido do sucesso dos fulerenos e dos nanotubos; e lança-se um projecto de investigação onde os átomos de carbono serão substituidos, em todos os lugares, por átomos de silicio. Este género de "avançadas" da ciência agradam, vejam lá, a muitos dos gestores da investigação.

$\mathrm{E}$, neste mesmo território cinzento e crepuscular, separando uma prática responsável, seguindo as regras da deontologia e da ética, duma prática irresponsável e criminosa, permitam-me que Ihes recorde alguns comportamentos mais ou menos delituosos: o colega que rouba bibliografia, fazendo um copypaste no computador, reproduzindo com todo o detalhe os erros de teclagem e de ortografia, sem nunca ter lido qualquer das referências que cita como base do seu trabalho. É plágio; e todos nós temos na cabeça exemplos doutros plágios.

Conhecemos também os abusos de avaliação dos pares. Que dizer do avaliador que arrasta, tanto quanto pode, a escrita do seu comentário subjectivo, abusando da sua notoriedade, para impedir um concorrente de publicar o seu trabalho, ou retardá-lo o mais possível.

E terminaria este capitulo triste com um aspecto da ciência química, também tẫo frequente que se tornou banal, a desnaturação da investigação e da tese de doutoramento, em proveito do empresariado e da exploração. Quantos laboratórios se tornaram em fábricas de fazer teses! Contentar-me-ei em recordar que, por definiçāo, um doutor é capaz, em princípio, de animar e dirigir um grupo de investigação. Recordarei também que, em princípio, qualquer signatário duma publicação é capaz de responder a qualquer questão que diga respeito a qualquer aspecto dessa publicaçăo - e não somente ao assunto da sua própria contribuiçãa.

\section{O investimento na indústria química}

E a indústria? Qual é o seu lugar nesta aventura? Terá ela de facto um lugar nesta aventura? Ou desconfiará ela de temperamentos aventurosos?

Pareceria que a aventura teria a sua presença no meio industrial, a ter em conta as monumentais guerras comerciais - as únicas que conhecem actualmente os paises mais ricos - a que se entregam as grandes multinacionais. A todo o momento, estão em guerra aberta ou intermitente: os geniozinhos do marketing - já nem se contam os seus erros - preparam ao intento dos comerciantes argumentações prendendo com alfinetes qualidades e defeitos dos produtos da concorrência. E, no laboratório, entregam-se a uma investigação qualificada de defensiva: trata-se, sem nada modificar no produto em que se investiu, de se tornar capaz de intervir contra o produto do concorrente. No caso deste se ter apoderado duma parte do mercado demasiado grande, então teremos armas para lutar, por meio dum produto semelhante ao seu e que apresente melhores resultados - quer seja por uma inovaçāo do produto, quer seja por uma inovação do processo.

Estas guerras industriais e comerciais são extremamente estimulantes para a investigação. 0 mais frequente, com efeito, é o estado-maior da corporação pedir aos seus nvestigadores que encontrem um defeito na coiraça do inimigo - e creio que isto consiste na parte maior do trabalho dos analistas, tão numerosos na indústria - ou, entâo, elaborar um produto melhorado. Fui eu mesmo testemunha privilegiada, há alguns anos, como consultor de uma das partes, de uma destas "guerras das lixivias" a que se entregam periodicamente as três ou quatro grandes corporações que partilham o mercado dos detergentes. Estou, portanto, em condições de exprimir a minha admiração pela química ultra-sofisticada, engenharia genética e química bioinorgânica aí compreendida, que sustenta as subtis formulações que nós metemos dentro das nossas máquinas de lavar.
Consequentemente, a aventura industrial é, acima de tudo, uma aventura guerreira, de regimentos, de brigadas e de divisões, que tenta aumentar o território comercial de uma firma e, portanto, os seus benefícios.

Mas a aventura industrial, igualmente desligada do laboratório, encontra-se maioritariamente em acções de comando, na tentativa de conquistar terras nunca antes exploradas. A investigação alveja então um produto inteiramente novo, definindo uma ameia ainda inexistente. Entre os produtos recentes que mexem com a quimica, lembrarei apenas nesta categoria os blocos-notas "amarelinhos", as fraldas descartáveis Dodot, os lípidos comercializados sob o nome genérico de Olestra, o tecido GoreTex, impermeável mas que deixa passar o vapor de água, e as aramidas, portanto, o Kevlar.

Impõe-se aqui uma observação irónica: à mínima provocação, cantam-nos as loas do liberalismo integral. 0 mercado leva a palma: e, por definição, o mercado é irrefutável, o seu julgamento é definitivo, dizem-nos. 0 paradoxo, bem real, é que as indústrias estão constantemente em busca de uma situação de monopólio não-concorrencial, de tal modo que Ihes permita arrecadar lucros colossais, pois, a partir daí, podem fixar os preços de venda no nível que thes for mais vantajoso. Cantam-nos as virtudes do mercado e da concorrência; mas todos os seus esforços visam subtrair-se a ele!

Uma vez que estou com veia satírica, permitam-me focar dois outros pequenos pontos de oposição à filosofia capitalista. O primeiro consiste numa observação de pouca monta. 0 gosto da aventura, para muitos industriais, deve ser entendido como gosto e incentivo do lucro. Ora o lucro é, pelo aspecto dos dividendos e do valor da cotação das acções na Bolsa, o que dá satisfação aos accionistas. Estes últimos são jogadores, como no casino; mas estes jogadores têm eles próprios a ilusão condescendente de que vão ganhar num instante. No entanto, qualquer probabilista nos dirá que, em todos os jogos de soma nula, haverá necessariamente ga- 
nhadores e perdedores. Assim, o gosto da aventura confunde-se vezes de mais, na indústria, com o seu próprio oxímero, o ganho assegurado. É uma das razões pelas quais as empresas, procurando precaver-se em relação a um risco demasiado grande, unem parceiros entre si, o que se designa pela expressão inglesa joint ventures.

Vejamos agora o segundo ponto: a indústria, a indústria química em particular, vê com bons olhos a sua investigação ser subsidiada pelo poder público, pelos laboratórios do Estado, como o CNRS em França. Deste modo, os contribuintes, isto é, o conjunto da nação, financiam os accionistas das grandes sociedades que embolsarão os beneficios, tornados possíveis pela investigação fundamental efectuada a montante, com longos anos de antecedência. A Comunidade Europeia encoraja fortemente, na hora actual, tais mecanismos de assistência à investigação aplicada mesmo que acabem estrangulando a investigação pura.
Eu tinha de fazer estas pequenas rectificações, a fim de contrariar aquela noção demasiado espalhada, segundo a qual não há qualquer risco na investigação universitária, enquanto que, pelo contrário, a investigação aplicada implica uma permanente tomada de riscos.

\section{Conclusão}

0 que se deve reter desta exposição? Uma vez que a aventura tem um papel tão importante no nosso ofício, como fazê-la estabelecer-se, prosperar e frutificar? Pelo exemplo. Com efeito, nós temos, nós podemos estar orgulhosos da nossa tradição, que remonta à alquimia, duma transmissão do saber dum mestre para um discípulo, ou um aprendiz. Como melhor inculcar o espírito de aventura, o gosto pela exploração fora dos atalhos batidos, do que tirando partido desta relação privilegiada? Incumbe-nos, pois, no ensino laboratorial que nos é próprio, velar pela preservação da parcela do imprevisto, a da curiosidade em todos os azimutes. Estou convencido de que a aptidão para o deslumbramento é inseparável do espírito de aventura. Conhecem a palavra de Diaghilev espanta-me! Devia ser esta a nossa frase-mestra perante qualquer jovem cujo trabalho supervisionamos.

A aventura química é também o respeito pelo inconformismo e pelos inconformistas. Na prática, se é bem verdade que actualmente o futuro e o horizonte da química está na biologia, isto não significa, de forma alguma, que nós devêssemos refrear as investigações em qualquer outro domínio. Não será necessário que a química biológica se torne um novo conformismo, a prioriesterilizante.

Terminarei citando a frase do revolucionário Danton, que podem ver inscrita no pedestal da sua estátua, na praça do Odéon, em Paris: audácia, ainda audácia, sempre audácia!

\title{
ve vider
}

\author{
Equipamento de Laboratório \\ Balanças - Centrifugas - Aparelhos de $\mathrm{pH}$ - Tituladores \\ Condutímetros - Agitadores - Espectrofotómetros \\ Microscópios - etc.
}

\section{Vidros e Plásticos de Laboratório} Distribuidores NORMAX

\section{Material Didáctico}

Ensino Secundário e Superior

Representantes exclusivos SISTEDUC - Sistemas Educativos S.A. 